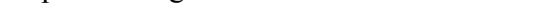

\title{
Proto-South China Sea Plate Tectonics Using Subducted Slab Constraints from Tomography
}

\author{
Jonny Wu*, John Suppe \\ Department of Earth and Atmospheric Sciences, University of Houston, Houston TX 77004, USA \\ (iD Jonny Wu: https://orcid.org/0000-0001-5530-005X; iDohn Suppe: https://orcid.org/0000-0003-0673-1683
}

\begin{abstract}
The past size and location of the hypothesized proto-South China Sea vanished ocean basin has important plate-tectonic implications for Southeast Asia since the Mesozoic. Here we present new details on proto-South China Sea paleogeography using mapped and unfolded slabs from tomography. Mapped slabs included: the Eurasia-South China Sea slab subducting at the Manila trench; the northern Philippine Sea Plate slab subducting at the Ryukyu trench; and, a swath of detached, subhorizontal, slab-like tomographic anomalies directly under the South China Sea at 450 to $700 \mathrm{~km}$ depths that we show is subducted 'northern proto-South China Sea' lithosphere. Slab unfolding revealed that the South China Sea lay directly above the 'northern Proto-South China Sea' with both extending 400 to $500 \mathrm{~km}$ to the east of the present Manila trench prior to subduction. Our slab-based plate reconstruction indicated the proto-South China Sea was consumed by double-sided subduction, as follows: (1) The 'northern proto-South China Sea' subducted in the Oligo-Miocene under the Dangerous Grounds and southward expanding South China Sea by in-place 'self subduction' similar to the western Mediterranean basins; (2) limited southward subduction of the proto-South China Sea under Borneo occurred pre-Oligocene, represented by the $800-900 \mathrm{~km}$ deep 'southern proto-South China Sea' slab.

KEY WORDS: seismic tomography, plate tectonics, South China Sea, proto-South China Sea, subducted slabs, Borneo, Oligocene-Miocene.
\end{abstract}

\section{INTRODUCTION}

The present tectonic setting near South and East China is characterized by subduction of the South China Sea and Philippine Sea marginal seas, which have been trapped by rapid westward Pacific Plate convergence towards Eurasia (Fig. 1a). Global plate reconstructions indicate convergent plate tectonics has been prevalent in East Asia since at least the Mesozoic (e.g., Seton et al., 2012). The predicted lithospheric subduction within these plate models is consistent with seismic tomographic images that show extensive slab-like, fast velocity anomalies within the East Asian mantle down to the coremantle boundary (Fig. 1a) (Hall and Spakman, 2015; Legendre et al., 2015; Zhao, 2015; Koulakov, 2011; Li and van der Hilst, 2010; Fukao et al., 1992). A recent analysis of subducted slabs from seismic tomography indicated the upper $1300 \mathrm{~km}$ of the East Asian mantle contains $7.16 \times 10^{7} \mathrm{~km}^{2}$ of subducted lithosphere (Wu et al., 2016). This implies that an immense area about one-seventh of the total Earth surface area has subducted under East Asia since $\sim 52 \mathrm{Ma}$ (Wu et al., 2016).

Despite general agreement on a long-lived history of subduction at East Asia, tectonic interpretations of East Asia

*Corresponding author: jwu40@central.uh.edu

(C) The Authors 2018. This article is published with open access at Springerlink.com

Manuscript received April 21, 2017.

Manuscript accepted July 15, 2017. mantle images have been non-unique and controversial, particularly for slab-like, tomographic anomalies that do not exhibit Benioff zone seismicity. One such example is the swath of sub-horizontal, slab-like anomalies directly under the present South China Sea at 450 to $700 \mathrm{~km}$ depths that we call the 'proto-South China Sea north slabs' (Fig. 1a), which will be the topic of this study. It has been proposed that a proto-South China Sea ocean basin existed south of the Eurasia-South China continental margin prior to the present South China Sea (e.g., Taylor and Hayes, 1983; Holloway, 1982). However, the whereabouts of the subducted proto-South China Sea lithosphere is controversial (Wu et al., 2016; Hall and Spakman, 2015; Zahirovic et al., 2014; Hall, 2002; Rangin et al., 1999). Furthermore, it has been questioned whether a proto-South China Sea even existed at all (Replumaz and Tapponier, 2003).

The goals of this study are to: (1) deduce proto-South China Sea Plate tectonics by mapping and unfolding slabs from tomography and placing them into a plate reconstruction context (cf., Wu et al., 2016); (2) briefly discuss the plausibility of our slab-based proto-South China Sea Plate tectonic reconstruction relative to previous studies; and, (3) comment on how slab unfolding can provide a relatively independent test of seismic tomographic image quality that can complement current seismic-based resolution tests.

1 DATA AND METHODS

1.1 Tomographic Model

The subducted slabs in this study were mapped from 


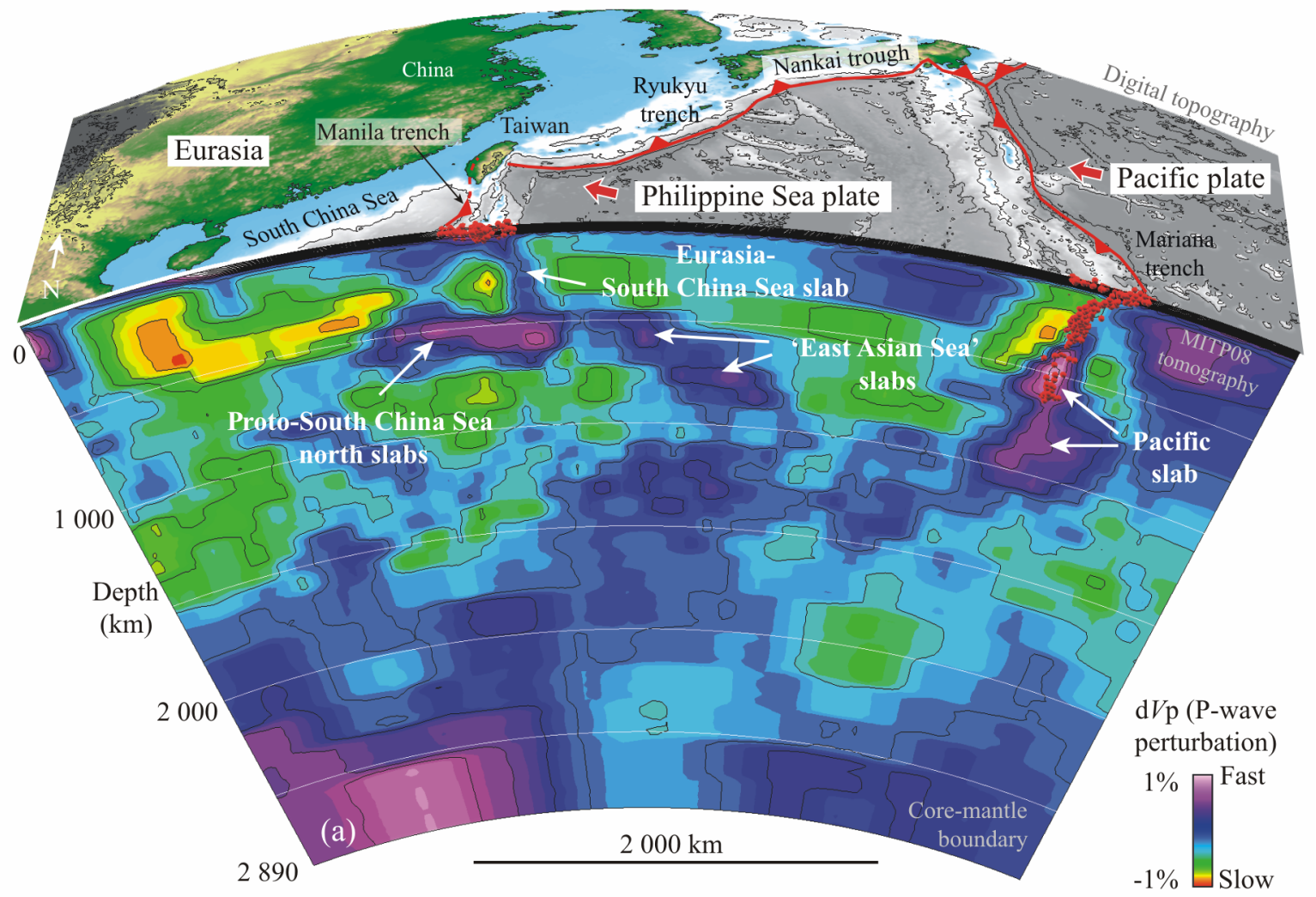

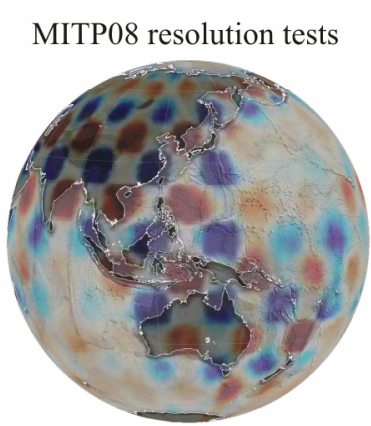

(b) $450 \mathrm{~km}$ depth

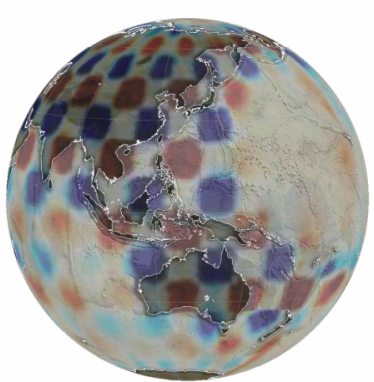

(c) $750 \mathrm{~km}$

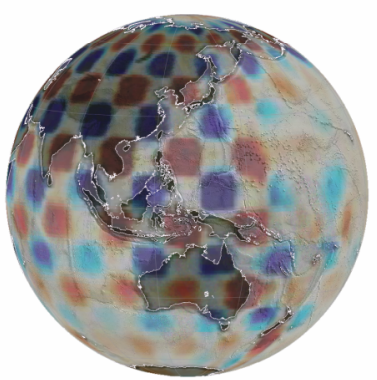

(d) $1350 \mathrm{~km}$

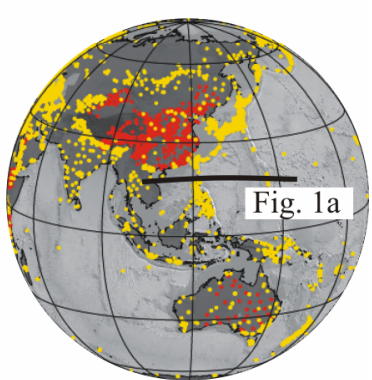

(e) Seismic stations

Figure 1. (a) East-west tomographic cross-section of the East Asian mantle under the Eurasian-South China Sea margin, the Philippine Sea and the western Pacific from MITP08 seismic tomography (Li et al., 2008). Cross-section location is shown in (e). Benioff zone seismicity is shown by red spheres in Fig. 1a. The East Asian mantle shows numerous fast P-wave velocity, slab-like tomographic anomalies at known and predicted past subduction zones that is consistent with a long-lived history of convergent plate tectonics at East Asia. (b) to (d) MITP08 checkerboard resolution tests indicate adequate tomographic resolution under East Asia. (e) Colored dots showing the seismic stations used in MITP08 tomography-EHB catalog (Engdahl et al., 1998) in gold; other stations in red. The MITP0 tomography was augmented by the Chinese seismographic network within East Asia (red dots within China in Fig. 1e).

MITP08 P-wave global tomography (Fig. 1) (Li et al., 2008), which has been widely used to study East Asian mantle structure for plate tectonic analyses (Wu et al., 2016; Zahirovic et al., 2016; $\mathrm{Lu}$ et al., 2013). The MITP08 model contains records from the global seismic catalog (Engdahl and Villaseñor, 2002; Engdahl et al., 1998) and is augmented by the Chinese Seismographic Network (red dots within China in Fig. 1e). The MITP08 model has a maximum $100 \mathrm{~km}$ resolution but as with other tomographic models, the resolution is spatially-variable and not easily quantified. Qualitative checkerboard tests indicate sufficient resolution within the East Asian mantle at relevant depths (Figs. 1b to 1d). Visually, the MITP08 model generally shows slab-like fast Pwave perturbation $(\mathrm{d} V \mathrm{p})$ anomalies that correspond to Benioff seismicities under known subduction zones (Fig. 1a).

\subsection{Slab Mapping}

Slabs were mapped from tomography using GOCAD software following a 3D slab mapping workflow described by $\mathrm{Wu}$ et al. (2016). Our mapped slabs generally had spatially continuous $\mathrm{d} V \mathrm{p}$ anomalies that were $0.2 \%$ to $1 \%$ faster than the surrounding mantle and exhibited steep velocity gradients at the slab edges. The slab models used in this study included the Eurasia-South China Sea slab and the northern Philippine Sea 'Ryukyu' slabs from Wu et al. (2016). The proto-South China Sea slab models in this study were slightly revised from $\mathrm{Wu}$ et al. (2016) based on a new, finer-scale tomographic mapping. 


\subsection{Slab Unfolding}

Wu et al. (2016) described a new plate reconstruction workflow that involved three slab unfolding methods, including (Fig. 2): (1) 'flexural unfolding' for relatively undeformed upper mantle slabs; (2) 'cross-sectional area slab unfolding' for highly deformed lower mantle slabs; and (3) 'radial unfolding' for subhorizontal lower mantle slabs. In 'flexural unfolding' a mid-slab triangulated surface is unfolded in three-dimensions to a spherical Earth surface, minimizing area and shape distortions (Figs. 2a, 2b). GOCAD software was used to perform the 3D flexural unfolding. In this paper we will demonstrate previous flexural unfolding results for the Eurasia-South China Sea slab and northern Philippine Sea slabs within the upper mantle. In 'cross-sectional area slab unfolding' (Figs. 2c, 2d) a cross-sectional slab area is measured from a tomographic transect and unfolded to the Earth surface using area conservation. Slabs were unfolded to a pre- subduction oceanic lithosphere thickness of 80 to $100 \mathrm{~km}$ depending on its predicted lithospheric age. Slab sub-areas are evaluated over a series of depth intervals (Fig. 2d), which allows a density correction to be applied at each depth to account for density-depth changes within the mantle following the PREM model (Dziewonski and Anderson, 1981). A suite of possible slab boundaries are considered by calculating cross-sectional slab areas from the range of $\mathrm{d} V \mathrm{p}$ velocity perturbation contours that can be 'closed' around the fast slab anomaly (Wu et al., 2016). This method was applied to reconstruct the western Pacific slabs by $\mathrm{Wu}$ et al. (2016), including the subducted Pacific slabs at central Marianas shown in Fig. 1a. In 'radial slab unfolding', sunken lower mantle flat slabs are assumed to have distorted by radial convergent downward flow (Fig. 2e). We reverse this process to unfold a mapped mid-slab surface to $660 \mathrm{~km}$ depth (Fig. 2f). The radially unfolded slab is then directly projected from 660

(1) 'Flexural' slab unfolding method
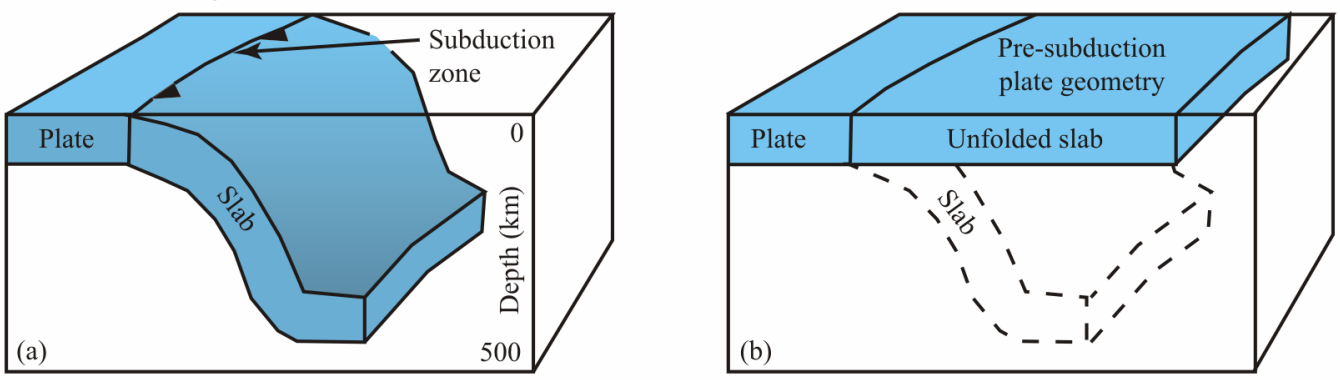

(2) 'Cross-sectional area' slab unfolding
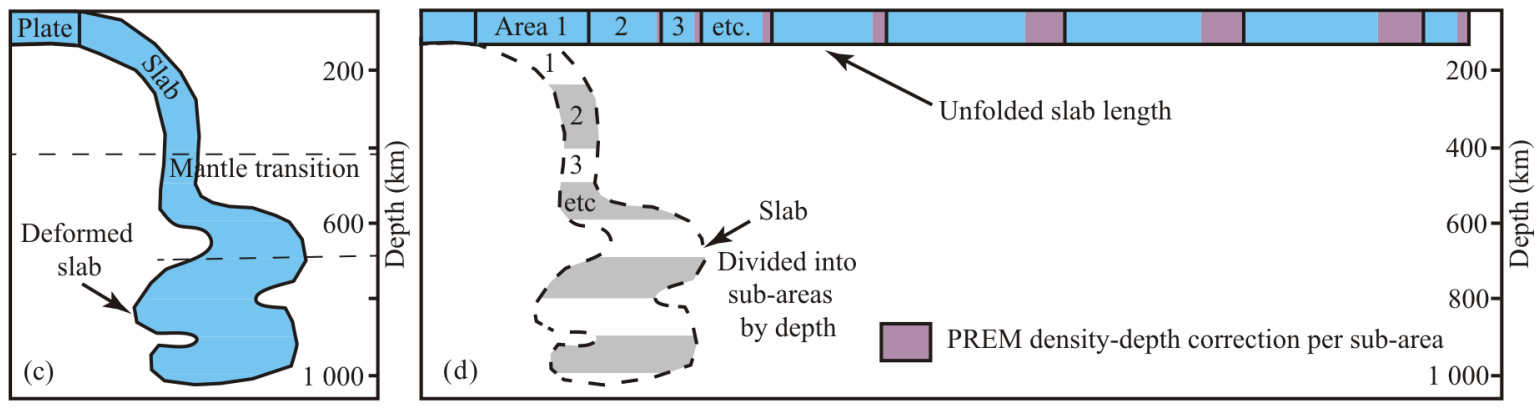

(3) 'Radial' slab unfolding
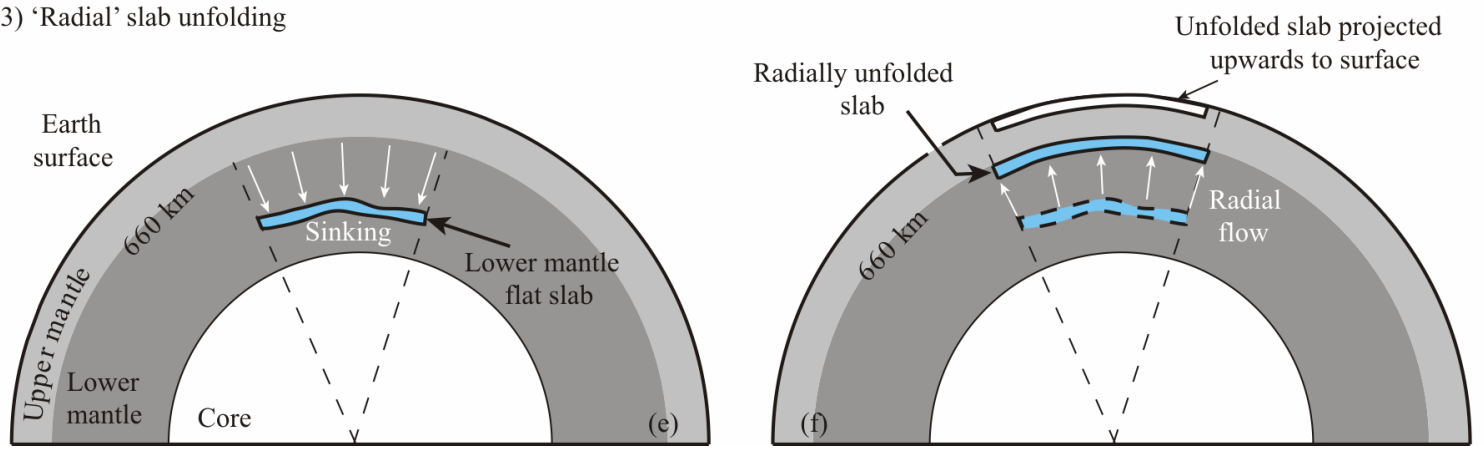

Figure 2. Slab unfolding methods used in this study (modified from Wu et al., 2016). (a) Geometry of a relatively undeformed upper mantle slab. (b) In flexural unfolding, the pre-subduction geometry of the mapped slab in (a) is estimated from a three-dimensional unfolding to a spherical Earth surface, minimizing area and shape distortions. (c) Geometry of a deformed lower mantle slab. (d) In cross-sectional area unfolding, the slab is unfolded back to the Earth surface in 2D using area conservation and an assumed initial oceanic lithosphere thickness of 80 to $100 \mathrm{~km}$ depending on the predicted slab lithospheric age. Slab sub-areas are divided by depth to enable a density-depth correction to be applied following the PREM Earth model (Dziewonski and Anderson, 1981). (e) A sunken lower mantle flat slab. (f) In radial unfolding, slab sinking and distortion by downward convergent radial flow is reversed by radially unfolding the flat slab back to the uppermost lower mantle at $660 \mathrm{~km}$ depth, followed by a projection to the earth surface from $660 \mathrm{~km}$ depth. 
$\mathrm{km}$ depth to a spherical model Earth surface for a plate reconstruction (Fig. 2f). Radial slab unfolding was only applied in this study as a minor correction to the proto-South China Sea slabs, which were at maximum $900 \mathrm{~km}$ depths within the uppermost lower mantle.

\subsection{Plate Reconstruction Framework}

The tectonic viability of the mapped and unfolded slabs was evaluated by adding our unfolded slabs into the framework of a global plate reconstruction using GPlates software (Boyden et al., 2011) following the $\mathrm{Wu}$ et al. (2016) workflow. We selected the global plate reconstruction of Seton et al. (2012) with minor modifications, as documented by $\mathrm{Wu}$ et al. (2016). The Seton et al. (2012) plate model framework used a rigid block approach that is appropriate for the regional-scale insights in this study but at smaller scales will display obvious gaps or overlaps at known non-rigidly deforming areas of Sundaland. As such, we will allow for some flexibility in our slab-based plate reconstruction to account for Borneo oroclinal bending (Hutchison, 2010) and uncorrected stretching of continental crust at the South China Sea margins, including the Dangerous Grounds (Bai et al., 2015). The global model also included a number of choices that are relevant for this study, and these are briefly reviewed below.

\subsubsection{South China Sea spreading kinematics}

Our selected plate model incorporated South China Sea spreading kinematics from Briais et al. (1993). However, other South China Sea spreading models have also been debated (cf., Sibuet et al., 2016; Li et al., 2014). Our tests showed the choice of an alternative South China Sea spreading model (i.e., Barckhausen et al., 2014) would slightly (within $5 \mathrm{Ma}$ ) alter our predicted subduction timings for the proto-South China Sea north slabs, but these models still robustly produced a double-sided proto-South China Sea subduction, which was a key conclusion of our plate models. The absolute positioning of the South China Sea was determined from the moving hotspot mantle reference used by Seton et al. (2012). A slight eastward shift within uncertainties (i.e., a constant $\sim 200 \mathrm{~km}$ offset between 52 and $23 \mathrm{Ma}$, followed by a smooth interpolation between the 23 to 0 Ma positions) was added by $\mathrm{Wu}$ et al. (2016) to optimize the fit of the eastern Eurasia-South China Sea slab and proto-South China Sea north slab edges. We tested other alternative Eurasia-South China absolute positions (e.g., Zahirovic et al., 2014; Hall, 2002) and other mantle references (Torsvik et al., 2008). We found these parameters did not materially change our plate modeling results because of the large size of our restored proto-South China Sea slabs (in excess of 2000 by $1500 \mathrm{~km}$ ) relative to the 200 to 300 $\mathrm{km}$ difference between alternative Eurasia absolute positions.

\subsubsection{Borneo motions}

The past motions and absolute positioning of Borneo have been widely debated (cf., Pubellier and Morley, 2014) and are important parameters for this study because they directly influence the subduction timing of the proto-South China Sea south slabs. We chose to maintain Borneo at a near-equatorial paleolatitude and applied $50^{\circ}$ counter-clockwise rotations based on paleomagnetism (Fuller et al., 1999), similar to many other studies (e.g., Hall, 2002). We chose to conclude rapid Borneo counter- clockwise rotations earlier than most studies at $\sim 35$ Ma based on new paleomagnetic samples from Cullen et al. (2012). Our choice meant that the proto-South China Sea south slabs were subducted under NW Borneo prior to $35 \mathrm{Ma}$ in our models, which we will later argue is consistent with their 750 to $900 \mathrm{~km}$ mantle depths relative to other regional slabs (Wu et al., 2016). Many Borneo plate models have also proposed that Borneo counter-clockwise rotations occurred later between 30 and $10 \mathrm{Ma}$ (i.e., Zahirovic et al., 2014; Hall, 2012), after Fuller et al. (1999). Use of the alternative Borneo motions in our plate models produced a corresponding 30 to $10 \mathrm{Ma}$ southward subduction of the 'proto-South China Sea south slabs' under NW Borneo but maintained an overall double-sided proto-South China Sea subduction zone configuration. This indicated that our overall modeled double-sided protoSouth China Sea subduction configuration was robust within the range of plate model choices, whereas the proto-South China Sea south slab subduction timings are sensitive to the input Borneo plate model. Therefore, we will include a discussion of alternative subduction time estimates for the proto-South China Sea south slabs within our plate model results.

\subsection{Spatial and Temporal Positioning of Unfolded Slabs within the Global Plate Model}

We reconstructed the spatial and temporal positioning of unfolded slabs within the global plate model by first determining whether a mapped slab was still 'attached' to a parent plate or wholly 'detached'. We considered the Eurasia-South China Sea slab and northern Philippine Sea slabs to be attached slabs. These slabs were input and moved with their associated 'parent' plate within the plate reconstruction. Seafloor spreading within these attached slabs was modeled by arbitrarily extending their GPlates polygons according to our unfolded slab lengths. Our proto-South China Sea slabs were not attached to any known subduction zone (e.g., Fig. 1a) and thus were considered detached slabs. These slabs were restored with minimal correction by simply positioning the radially unfolded slab above the centroid of the folded surface and kept static within the mantle reference to yield the most straightforward reconstruction. Other details of the slab reconstruction method are documented in Wu et al. (2016).

\section{RESULTS}

\subsection{D Slab Mapping from Tomography}

\subsubsection{South China Sea and proto-South China Sea slabs}

The Eurasian-South China Sea margin has subducted eastwards under the Philippine Sea Plate at the Manila trench. The 'Eurasia-South China Sea slab' displays Benioff zone seismicity down to a maximum $\sim 300 \mathrm{~km}$ depths (Fig. 3a). In plan view the Benioff seismicity occurs within a relatively narrow $\sim 300 \mathrm{~km}$ EW zone east of the Manila trench (Fig. 3a). The $280 \mathrm{~km}$ depth horizontal tomographic slice shows a discrete and narrow N-S fast slab anomaly to the east of the Manila trench that is subparallel to the trench and follows the Benioff seismicity (Figs. 3a, 3b). Our 3D mapping of the Eurasia-South China Sea mid-slab from MITP08 showed a slab anomaly that is sub-vertical at depth and extends to a maximum depth of $450 \mathrm{~km}$ (Figs. 1a, 3c, 4) (Wu et al., 2016).

The tomographic transects in both Figs. 1a and 4a across 

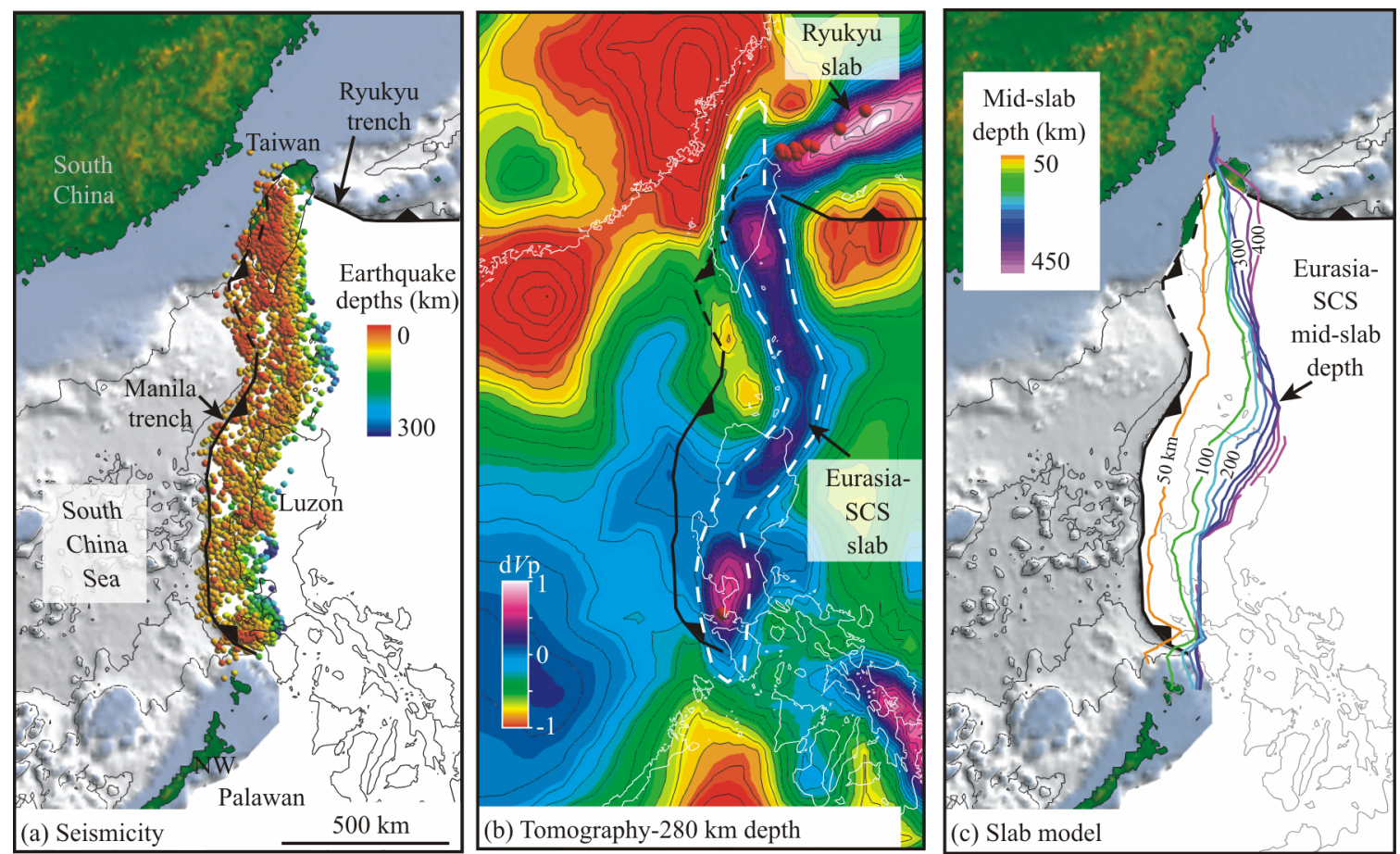

Figure 3. Eurasia-South China Sea (SCS) slab. (a) Map of Benioff zone seismicities within $50 \mathrm{~km}$ of the mid-slab surface; (b) Eurasia-SCS slab anomaly from a $280 \mathrm{~km}$ horizontal tomographic section; and (c) depth contours from the Eurasian-SCS mid-slab model of Wu et al. (2016).

the SE Manila trench and South China Sea show a clear Eurasia-South China Sea slab anomaly that is nearly vertical at a depth of $\sim 400 \mathrm{~km}$. Our unfolding of the Eurasia-South China Sea slab (see black dashed lines in Fig. 4a) indicates the South China Sea previously extended $\sim 400$ to $500 \mathrm{~km}$ east of the present Manila trench (Figs. 4a, 5a). This would imply the South China Sea once extended eastwards to the longitude of the Yaeyama Islands, Japan, prior to subduction (Fig. 5a).

The tomographic sections also show deeper, detached, sub-horizontal fast slab anomalies within the mantle transition zone and lower mantle at 450 to $700 \mathrm{~km}$ depths that we call the 'proto-South China Sea north' slabs (Fig. 4a). These slabs have been previously identified from other tomography but there has been little agreement on their origin (e.g., Zahirovic et al., 2016; Hall and Spakman, 2015; Huang et al., 2015; Obayashi et al., 2013; Rangin et al., 1999). Our mapping of the protoSouth China Sea north slabs from MITP08 tomography (updated from $\mathrm{Wu}$ et al., 2016) revealed their extent was largely under the present South China Sea and the westernmost Philippine Sea (Fig. 5b). We note the lack of fast tomogrpahic slab anomalies south of Borneo in the upper $660 \mathrm{~km}$ (Fig. 4a), where most published studies have predicted relatively recent proto-South China Sea subduction in the Miocene (e.g., Hutchison et al., 2000). Our slab unfolding revealed both the unfolded Eurasia-South China Sea slab and the 'proto-South China Sea north slabs' had eastern limits that were 400-500 $\mathrm{km}$ east of the present Manila trench and were oriented northsouth (compare dashed purple lines in Fig. 5a). We will later show in Section 2.2.2 that the similar unfolded eastern edges is a key observation from this study because it enables a shared South China Sea/proto-South China Sea Plate boundary transform when placed within a plate tectonic reconstruction.
We also updated our previous Wu et al. (2016) mapping of the 'proto-South China Sea south slabs', which are a swath of sub-horizontal slabs at 750 to $900 \mathrm{~km}$ depths under NW Borneo and the SW South China Sea (Figs. 4b, 5b). It is important to note that the proto-South China Sea south slabs are relatively deeper (750 to $900 \mathrm{~km}$ ) than the "proto-South China Sea north slabs' at 450 to $700 \mathrm{~km}$ depths (Figs. 4, 5). Assuming constant slab sinking, this apparently suggests the deeper proto-South China Sea south slabs were subducted prior to the shallower north slabs. Our preferred plate reconstruction shown later is consistent with this inferred subduction sequence.

\subsubsection{Northern Philippine Sea slab}

The Philippine Sea has subducted northwards under Eurasia at the Ryukyu trench. The 'Ryukyu slab' subducted along the Ryukyu trench shows clear Benioff seismicity and a trenchparallel fast tomographic anomaly between 100 to $280 \mathrm{~km}$ depths (Figs. 6a, 6b). The Nankai trough segment of the northern Philippine Sea slab (i.e., Shikoku slab) exhibits Benioff zone seismicity above $200 \mathrm{~km}$ depths but is not well-imaged (Figs. 6a, 6b), probably due to a lack of thermal anomaly from a young lithospheric age during subduction (Wu et al., 2016). At $400 \mathrm{~km}$ depths the Ryukyu slab tomographic anomaly dramatically widens to the north (Fig. 6c) due to flattening above deeper stagnant Pacific slabs, as shown by Wu et al. (2016).

Our 3D mapped northern Philippine Sea mid-slab model shows an arcuate, flat-bottomed shape (Fig. 6d). The northwestern limit of the Ryukyu slab extends north from Taiwan to East China near Shanghai at $\sim 400 \mathrm{~km}$ depths (Fig. 6c). Unfolding of the Philippine Sea Plate slabs including detached Shikoku slab remnants under Japan revealed the northern Philippine Sea Plate was $\sim 700$ to $1000 \mathrm{~km}$ longer prior to subduction (Fig. 6e) (Wu 

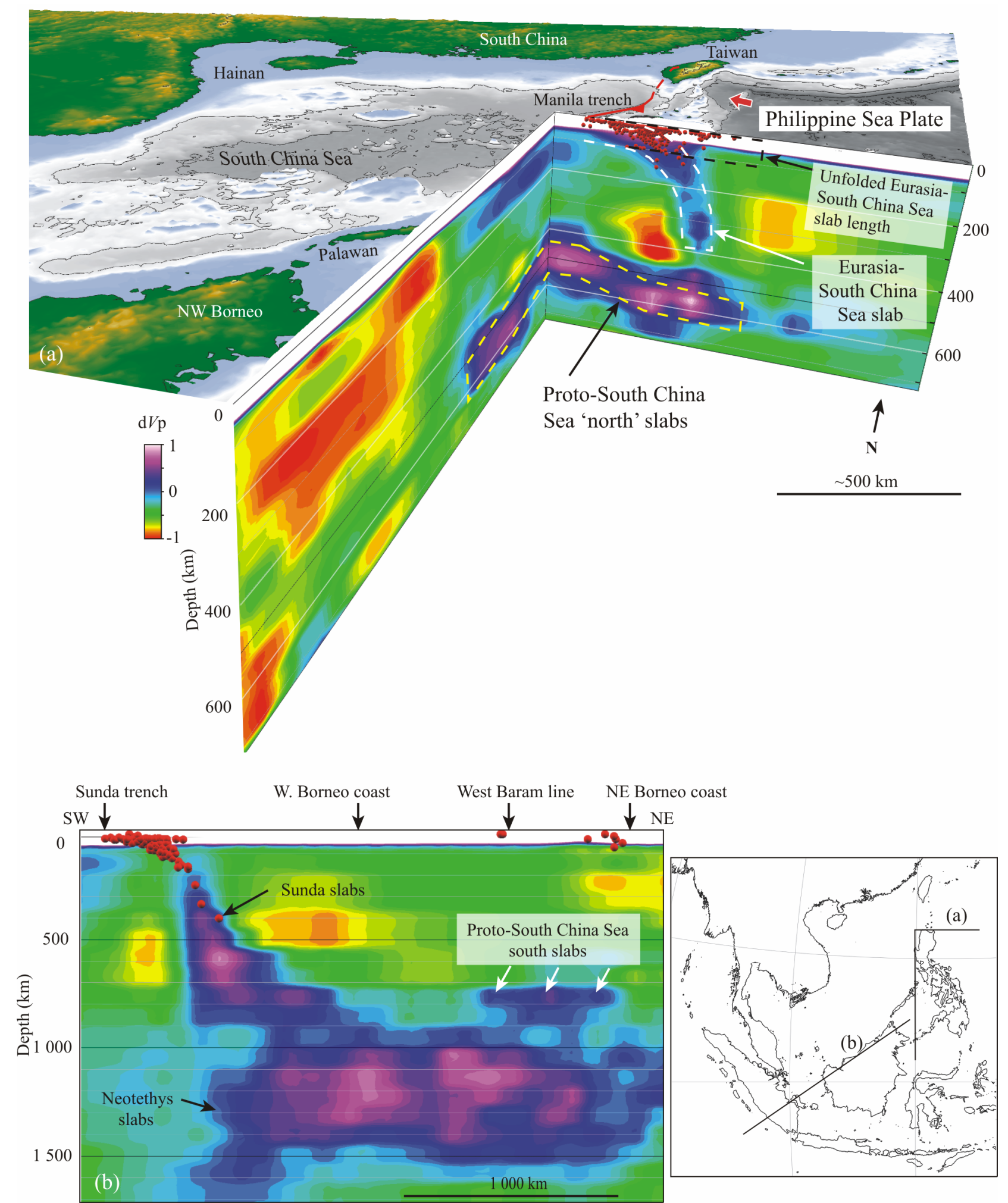

Figure 4. MITP08 tomographic sections showing examples of the mapped South China Sea and proto-South China Sea slab anomalies. Location map shown at lower right. Projected seismicity shown by red spheres. (a) 3D oblique view of E-W and N-S tomographic cross-sections across the SE South China Sea and a digital elevation model overlay. The South China Sea slab has been subducted to $\sim 400 \mathrm{~km}$ depths below the Manila trench. The detached, sub-horizontal 'protoSouth China Sea north slabs' lie below the South China Sea and westernmost Philippine Sea at 450 to $700 \mathrm{~km}$ depths. Slab unfolding of the Eurasia-SCS slab (black dashed line) reveals the South China Sea once extended 400-500 km east of the Manila trench prior to subduction, which is coincident with the present eastern limit of the proto-South China Sea north slabs. (b) Tomographic section showing the proto-South China Sea south slabs at 700 to $900 \mathrm{~km}$ depths below northern Borneo. 

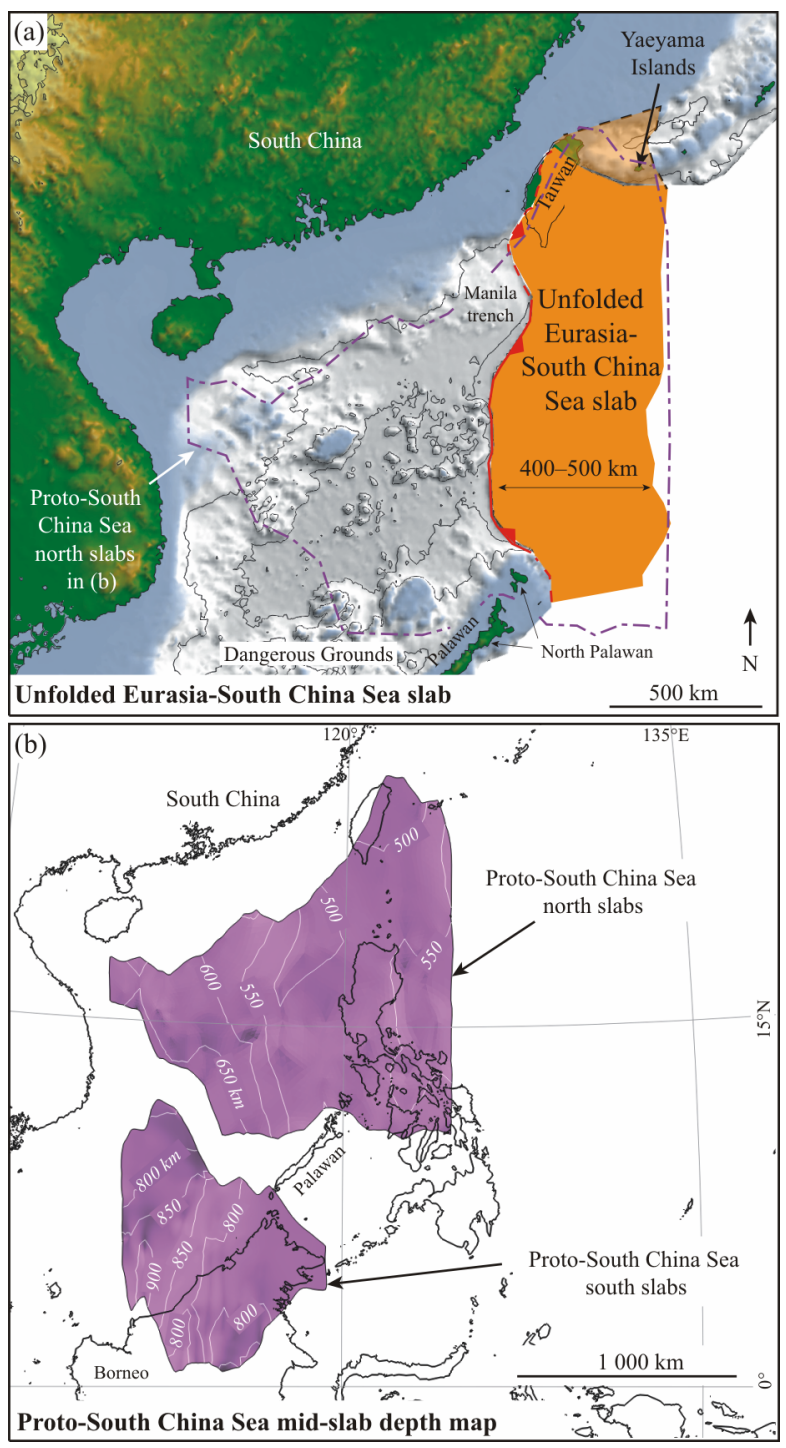

Figure 5. (a) Map showing the unfolded extent of the Eurasia-South China Sea slab (orange area) after Wu et al. (2016). The slab unfolding implies the South China Sea once extended 400-500 km east of the present Manila trench and terminated northwards near the Yaeyama Islands, Japan. (b) Mapped extent of the proto-South China Sea slabs in purple. The 'protoSouth China Sea north slabs' are below the present South China Sea at $\sim 450$ to $700 \mathrm{~km}$ depths. The 'proto-South China Sea south slabs' are below the southern South China Sea and northern Borneo at 750 to $900 \mathrm{~km}$ depths (updated from Wu et al., 2016). The comparison in (a) highlights the similar eastern edge of the proto-South China Sea north slabs (purple dashed line) and the unfolded Eurasian-South China Sea slab. When reconstructed within a plate model (see Fig. 7, ESM2 ProtoSCS_plate_ model_movie.mov), the restored eastern edges fit together as a shared South China Sea/proto-South China Sea N-S plate boundary transform.

et al., 2016). The western edge of the unfolded northern Philippine Sea Plate shows a prominent N-S western edge that extends $\sim 1000 \mathrm{~km}$ north of Taiwan (Fig. 6e).

\subsection{Plate-Tectonic Reconstruction Using Unfolded Slab Con-} straints

\subsubsection{Pre-Oligocene period}

Input of the unfolded slabs into a global plate reconstruction revealed a general fit of our restored proto-South China Sea slabs between South China and northern Borneo at $50 \mathrm{Ma}$ (see ESM2 ProtoSCS_plate_model_movie.mov) within uncertainties as outlined in Section 1.4. Reconstruction of the slabs within the plate model framework forward from 50 Ma revealed a doublesided subduction of the proto-South China Sea, as described below (Figs. 7, 8, ESM2 ProtoSCS_plate_model_movie.mov). After $50 \mathrm{Ma}$, counter-clockwise rotation of Borneo produced a southward subduction of the 'proto South China Sea south slabs' under NW Borneo (see ESM2 ProtoSCS_plate_model movie. mov). Southward proto-South China Sea subduction concluded by the Mid- to Late Eocene based on our modeled $50^{\circ}$ counterclockwise Borneo rotation timings (see Section 1.4). The end of our modeled southward subduction coincides with the 'Sarawak orogeny', an important period of uplift and denudation that affected NW Borneo along Sarawak, central Sabah and southern Palawan that occurred in the Mid-Eocene 45 Ma (Hutchison, 1996), or Eocene to Early Oligocene (Cullen, 2010). Other studies have also linked the Sarawak orogeny to the final phase of deformation of a remnant basin (Hall, 2012) or final southward consumption of the proto-South China Sea (Pubellier and Morley, 2014). Our slab constraints can not rule out a younger $\sim 30$ to 10 Ma subduction of the southern proto-South China Sea under Borneo if a younger Borneo counterclockwise rotation model is implemented (i.e., Zahirovic et al., 2014; Hall, 2002) (see Section 1.4). However, we prefer our Earlier Eocene subduction time for the proto-South China Sea south slabs because their present 750 to $900 \mathrm{~km}$ depths are consistent with other East Asia slabs that were subducted in the Oligocene to Eocene (Wu et al., 2016).

\subsubsection{Oligocene to present}

South China Sea seafloor spreading after $\sim 34$ Ma initiated a second phase of proto-South China Sea subduction that was characterized by northward subduction of the 'proto-South China Sea north slabs' under the Dangerous Grounds and north Palawan (Figs. 5a, 7a, 8a) (Wu et al., 2016). An important aspect of our model is the shared easternmost South China Sea/proto-South China Sea Plate boundary transform (Figs. 7a, 7b). This feature was enabled by the remarkably coincident positions of the unfolded Eurasia-South China Sea and protoSouth China Sea north slab eastern edges (Figs. 5b, 7). Our modeled northward subduction implied a maximum $\sim 4.2 \mathrm{~cm} / \mathrm{yr}$ long-term average subduction rate (i.e., $800 \mathrm{~km}$ subduction between 34 to $15 \mathrm{Ma}$ ), which fits within global plate tectonic speed limits (Zahirovic et al., 2015) and is about half the present Pacific-Eurasia convergence rate near Japan. Seafloor spreading within the proto-South China Sea (e.g., Zahirovic et al., 2014) would increase the average subduction rate but was not modeled due to lack of constraints. Our modeled northward subduction of the 'proto-South China Sea north slabs' loosely fits a back arc-style subduction model. However, we prefer to call it a 'self-subduction' that is reminiscent of western Mediterranean tectonics since the Oligocene, in which the former Tethys Ocean was subducted and replaced by the present western Mediterranean Sea by subduction rollback without significant regional plate convergence (e.g., Faccenna et al., 2014; Spakman and Wortel, 2004).

In contrast to conventional proto-South China Sea Plate 

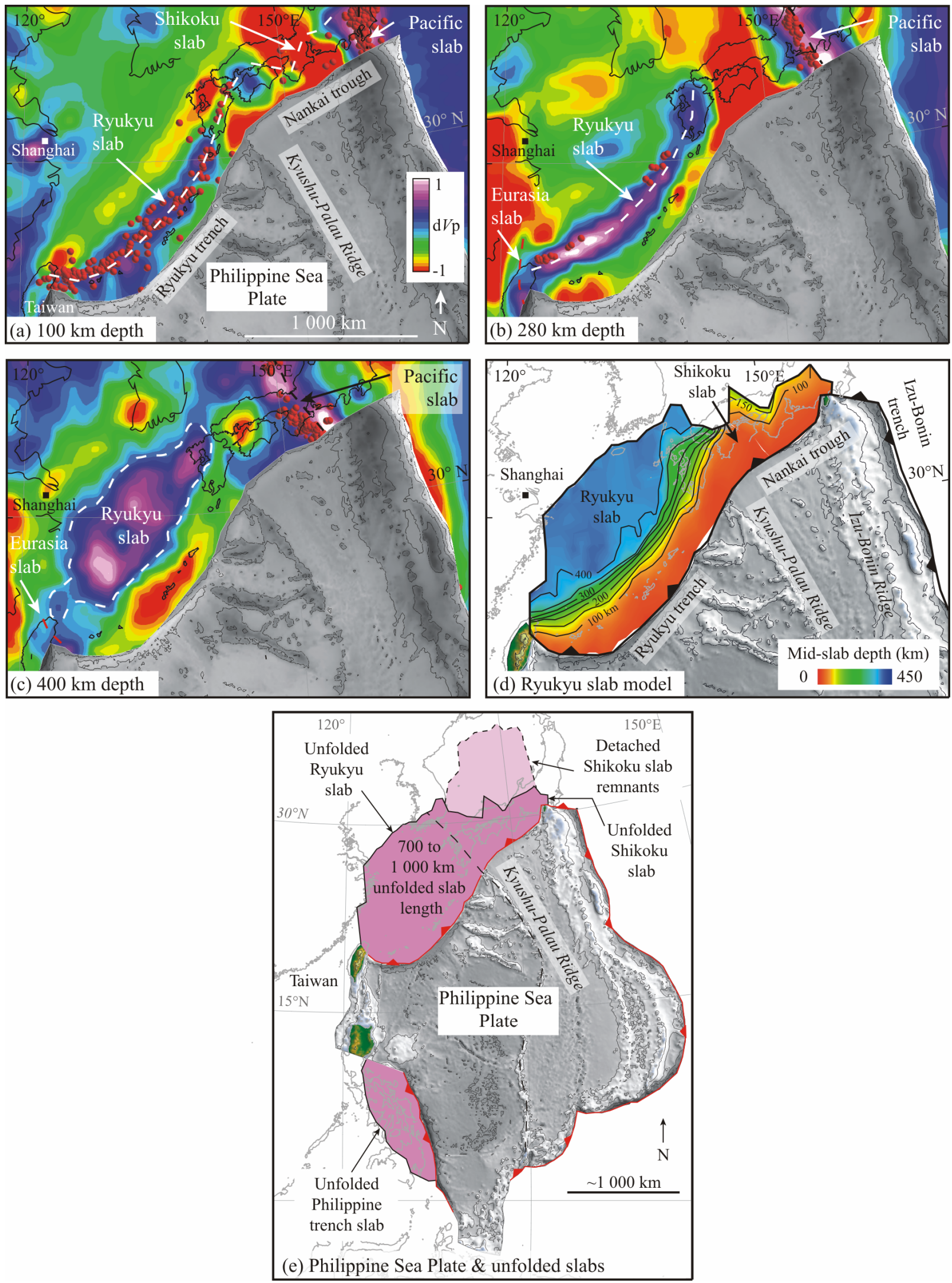

Figure 6. Summary of the Wu et al. (2016) slab model for the northern Philippine Sea slabs subducted at the Ryukyu trench and Nankai trough. MITP08 tomographic slab anomalies and seismicity (red spheres) at: (a) $100 \mathrm{~km}$ (b) $280 \mathrm{~km}$, and (c) $400 \mathrm{~km}$ depths. (d) Northern Philippine Sea mid-slab model based on (a) to (c). The Ryukyu slab has a N-S western edge that terminates northward in the mantle under eastern China near Shanghai. (e) Philippine Sea Plate DEM and unfolded slabs showing the restored pre-subducted size of the Philippine Sea from slab unfolding. The unfolded northern Philippine Sea slab length is 700 to $1000 \mathrm{~km}$ long and has a prominent N-S western edge north of Taiwan. 

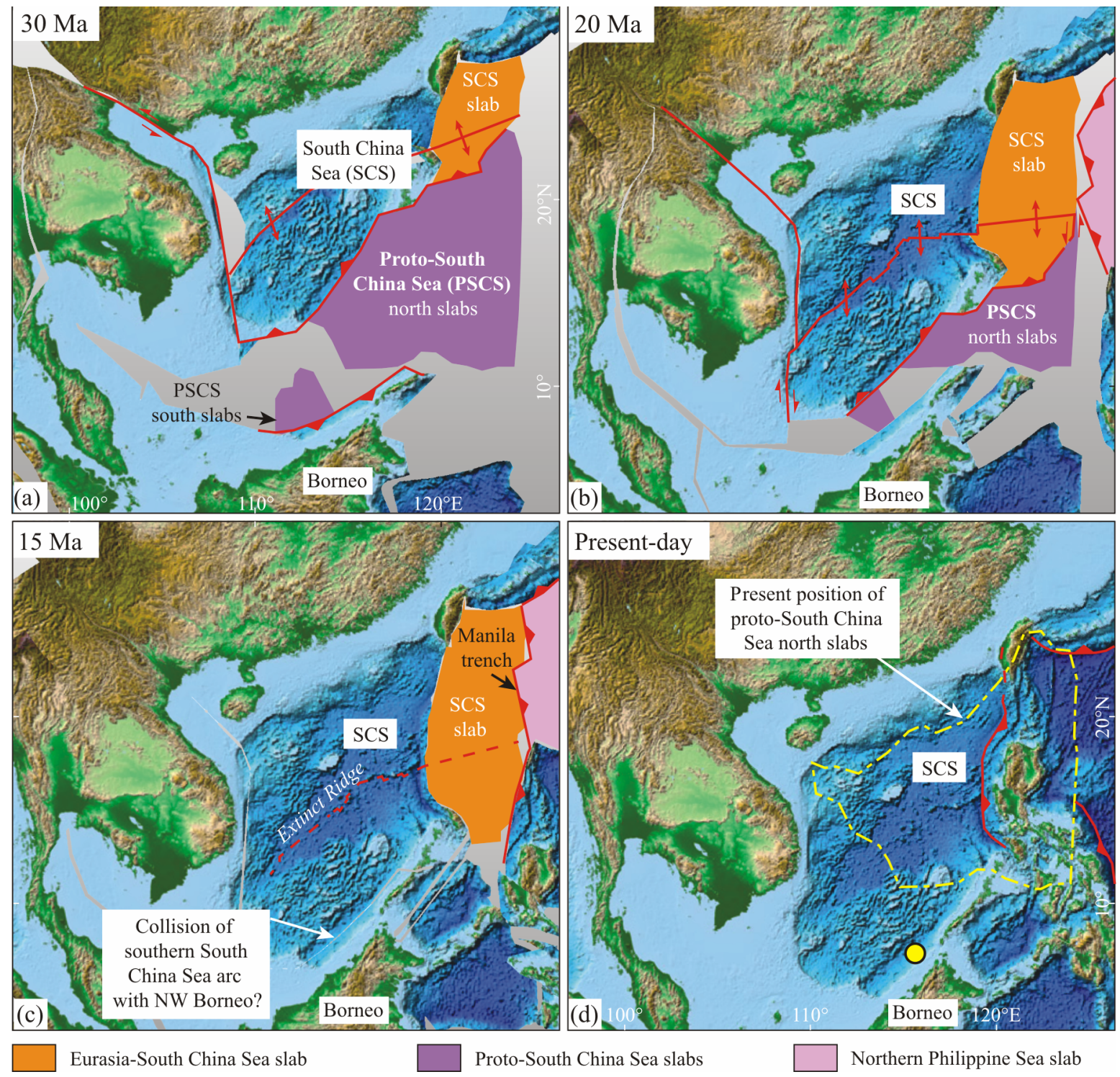

Figure 7. East Asia slab-based plate reconstruction showing northward subduction of the proto-South China Sea north slabs beneath the South China Sea after $30 \mathrm{Ma}$ (updated from Wu et al., 2016). The plate reconstruction was generated by adding our unfolded slab constraints into the global plate model of Seton et al. (2012). Small reconstruction gaps (in grey) and overlaps north of Borneo can be attributed to rigid plate model limitations (see Section 1.4). Other unfolded slabs from Wu et al. (2016) fill other reconstruction gaps east of Borneo and the proto-South China Sea (not shown here). (a) By 30 Ma the northern ProtoSouth China Sea represented by the north slabs began to subduct northwards under the Dangerous Grounds due to South China Sea opening. The southern South China Sea was an active margin. Northern Borneo may have been an active margin with slow subduction but the majority of the southern proto-South China Sea had subducted under northern Borneo prior to the Oligocene (see ESM2 ProtoSCS_plate_model_movie.mov). (b) By 20 Ma most of the northern proto-South China Sea had subducted northwards under the South China Sea. The northwestern Philippine Sea plate began to override the newly-formed South China Sea from the east along the Manila trench. (c) At 15 Ma the northern proto-South China Sea was completely subducted and South China Sea spreading terminated. A volcanic arc at the southern South China Sea margin collided with the NW Borneo margin and was underthrusted beneath Borneo. (d) At present, the proto-South China Sea north slabs (outlined by dashed yellow line) are represented by tomographic anomalies at $\sim 450$ to $700 \mathrm{~km}$ depths under the South China Sea and westernmost Philippine Sea Plate. The yellow dot in (d) shows a buried, elongate, higher velocity body at offshore NW Borneo (Franke et al., 2008) that could be fragments of a southern South China Sea accretionary complex or island arc.

reconstructions, our model predicts the southern Dangerous Grounds margin was an active margin at the leading edge of a subduction zone by $30 \mathrm{Ma}$ (Figs. 7a, 8a), and probably earlier based on Dangerous Grounds-South China continental breakup in the Latest Eocene (Barckhausen et al., 2014; Briais et al., 1993). An important aspect of our model is the implied mantle wedge under the South China Sea during seafloor spreading (Figs. 8a, 8b and 8c), which suggests that South China Sea open- ing was accompanied by a more vigorous asthenospheric circulation than previously recognized. Our placement of the southern Dangerous Grounds near a proto-South China Sea subduction zone provides a new explanation for observed Late Eocene compression within the Dangerous Grounds strata (Yan and Liu, 2004; Zhou et al., 1995) and Middle Eocene to Early Oligocene uplift and erosion at offshore northern and central Palawan (Schlüter et al., 1996). As noted by Cullen (2010), the 


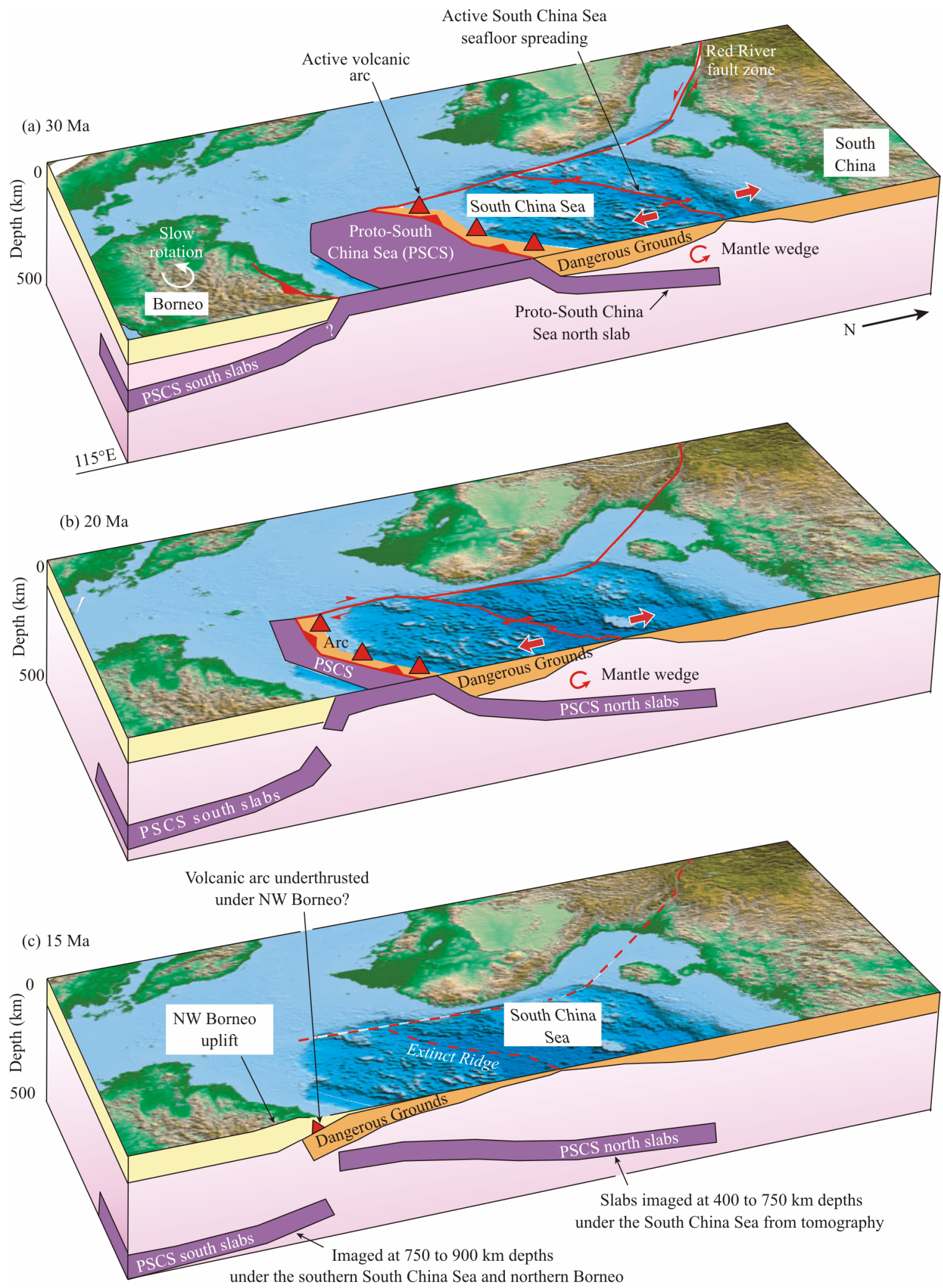

Figure 8. 3D block diagram showing double-sided subduction of the proto-South China Sea between 30 and 15 Ma based on slab constraints (Wu et al., 2016; this study). Opening of the South China Sea after $\sim 34$ Ma initiated northward subduction of the 'proto-South China Sea north slabs' beneath the southern Dangerous Grounds. Southward subduction of the 'proto-South China Sea south slabs' under northern Borneo occurred during the Eocene and possibly later due to counter-clockwise Borneo rotations, which are not well time-constrained. Our model implies that during South China Sea seafloor spreading, the southern Dangerous Grounds was an active margin and a mantle wedge formed under the South China Sea. As shown in (c), we suggest the predicted southern Dangerous Grounds volcanic arc was thrust under NW Borneo around $\sim 15 \mathrm{Ma}$ and is no longer at the Earth surface. 
compressional events noted above have been puzzling to explain using conventional proto-South China Sea Plate models, which have placed the Dangerous Grounds within a passive margin during Eocene to Early Oligocene, far from any active margin (e.g., Hall, 2012, 2002).

By $20 \mathrm{Ma}$, most or all of the northern proto-South China Sea was subducted northward under the South China Sea (Figs. $7 \mathrm{~b}, 8 \mathrm{~b})$. Stretched continental crust at the Dangerous Grounds leading edge had arrived or nearly arrived at NW Borneo, leading to a collision (Figs. 7b, 8b). Our predicted collision timing and configuration fits with previous models of the 'Sabah orogeny' at NW Borneo, a period characterized by prominent uplift and multiple unconformities (Hutchison et al., 2000; Holloway, 1982). Along the easternmost South China Sea Plate boundary, the western Philippine Sea approached from the east and began to override the South China Sea/proto-South China Sea (Fig. 7b). Subduction of the South China Sea under the Philippine Sea eastern edge after $20 \mathrm{Ma}$ produced the $\mathrm{Lu}-$ zon arc (Figs. $7 \mathrm{~b}$ to $7 \mathrm{~d}$ ).

Our plate model apparently requires the existence of a volcanic arc along the southern Dangerous Grounds leading edge (Figs. 7c, 8c). Our postulated 'southern South China Sea arc' would have collided with NW Borneo between 20 and 15 Ma (Figs. 7c, 8c). Although no remnant southern South China Sea arc has been identified along the NW Borneo margin to date, there is evidence that the Dangerous Grounds rifted continental crust continues far inland, under onshore NW Borneo (Cullen, 2010). Thus, we suggest our predicted arc was underthrust far beneath North Borneo (Fig. 8c). There is geophysical evidence for elongate, roughly margin-parallel, high-velocity $(V \mathrm{p} \sim 3.45 \mathrm{~km} / \mathrm{s}$ ) and high density bodies under the offshore NW Borneo margin - the so-called 'Major Thrust Sheet' (see yellow dot in Fig. 7d for location) (Franke et al., 2008; Hinz et al., 1989). These enigmatic features were most recently interpreted to be a carbonate layer or overthrusted Borneo-derived sediments mixed with proto-South China Sea crustal fragments (Franke et al., 2008). Our model suggests these features could also be fragments of our predicted southern South China Sea arc or its associated accretionary complex.

Our modeled double-sided subduction of the proto-South China Sea (e.g., Fig. 8) strongly contrasts with previous published models, which typically recognize only the southwards proto-South China Sea subduction under Borneo (Pubellier and Morley, 2014; Zahirovic et al., 2014; Hall, 2002; Taylor and Hayes, 1983). Below we discuss our new slab-based protoSouth China Sea Plate tectonic model relative to previous studies and summarize our main hypotheses. We will also comment on how slab unfolding can provide a plate tectonic test for subducted slabs imaged by seismic tomography.

\section{DISCUSSION}

\subsection{Comparison to Previous Proto-South China Sea Tec- tonic Studies}

Proto-South China Sea Plate tectonic reconstructions have important implications for the Mesozoic-Cenozoic tectonic history of SE Asia and Southeast China but continue to be controversial and uncertain (Sun et al., 2016; von Hagke et al., 2016; Wu et al., 2016; Zahirovic et al., 2016; Hall and
Spakman, 2015; Pubellier and Morley, 2014; Cullen, 2010). The deep slab anomalies under the South China Sea that we call the 'proto-South China Sea north slabs' have been identified by previous tomographic studies (Fan et al., 2017; Hall and Spakman, 2015; Huang et al., 2015; Rangin et al., 1999) but have not been directly linked to proto-South China Sea plate tectonics. One exception is Rangin et al. (1999), who identified the southern portion of these slabs as the proto-South China Sea but did not map their full extent (see discussion below). The double-sided proto-South China Sea subduction proposed here (Figs. 7,8) provides an explanation for the imaged slabs under the South China Sea (i.e., proto-South China Sea north slabs) that is consistent with vertical slab sinking, which is arguably the most straightforward tectonic interpretation (e.g., Domeier et al., 2016). The current mantle depths of the proto-South China Sea north slabs fits with other regional slabs that subducted during the Late Oligocene to Miocene (Wu et al., 2016). The proto-South China Sea slabs also show a good spatial fit within a regional East Asia Plate tectonic reconstruction back to $52 \mathrm{Ma}$ (Wu et al., 2016). Therefore, at the very least, we argue the slab-based proto-South China Sea Plate tectonic model proposed here is an important challenge to conventional models that show only one-sided, southward proto-South China Sea subduction under NW Borneo (e.g., Hall, 2002; Taylor and Hayes, 1983).

Previous tomographic studies have proposed that our mapped 'proto-South China Sea north slabs' are unrelated to the proto-South China Sea but are instead older subducted slabs from the Cretaceous that stagnated in the mantle transition zone (Hall and Spakman, 2015). This interpretation contradicts global slab studies that indicate a maximum slab stagnation period within the transition zone of $60 \mathrm{Ma}$ (Goes et al., 2017). It would also require an anomalously slow slab sinking rate relative to other East Asia slabs at similar mantle depths (Wu et al., 2016). Some studies have interpreted that the 'proto-South China Sea north slabs' are of proto-South China Sea origin, but suggested the slabs subducted southwards under NW Borneo during the Miocene and then migrated laterally $\sim 1000 \mathrm{~km}$ within the mantle (Zahirovic et al., 2014). This interpretation would require long distance $(\sim 1000 \mathrm{~km})$ lateral slab migration within the upper mantle and transition zone during the Neogene (Zahirovic et al., 2014). We argue the proto-South China Sea reconstruction shown here (Figs. 7, 8) is more straightforward as it does not require significant lateral slab advection. Furthermore, our reconstruction is consistent with many other tomographic studies that have identified nearvertical slab sinking (e.g., Sigloch and Mihalynuk, 2013; van der Meer et al., 2009).

Rangin et al. (1999) mapped the southern portion of our 'proto-South China Sea north slabs' and similarly identified our southern slab limit under Palawan (Fig. 5b). However, their tomographic transects did not span the entire South China Sea (Rangin et al., 1999) and did not show the full proto-South China Sea slab extent (Fig. 5b). Rangin et al. (1999) concluded that the slabs were of proto-South China Sea origin. However, their reconstruction relied on strong clockwise Borneo rotations in the Neogene to produce southward proto-South China Sea subduction under Borneo and the Sulu Sea (Rangin et al., 
1999). Paleomagnetic studies have not supported strong Neogene clockwise Borneo rotations but instead indicate overall counter-clockwise Borneo rotations in the Cenozoic (Cullen et al., 2012; Fuller et al., 1999), which was employed in the plate reconstructions shown here. Whatever the case, neither Borneo rotation direction can sufficiently consume the northern and easternmost extent of the 'proto-South China Sea north slabs' recognized in this study (Fig. 5b). In contrast, our proposed double-sided subduction model easily consumes the northern proto-South China Sea by a sweeping northward subduction under the opening South China Sea (Figs. 7, 8).

'SE Asia extrusion'-styled plate tectonic reconstructions have proposed that north-south South China Sea opening was exclusively accommodated by outboard subduction along southern Sundaland margin (i.e., southern Indonesia), far to the south of Borneo; a 'proto-South China Sea' did not exist (Replumaz and Tapponier, 2003). Because the extrusion model does not allow for Cenozoic subduction within the present South China Sea region, this model is apparently incompatible with our mapped slabs under the South China Sea and northern Borneo (Figs. 4, 5b) unless our mapped slabs are interpreted as older Mesozoic slab fragments, similar to Hall and Spakman (2015). However, this scenario requires unconventional slab sinking dynamics, as discussed above.

Cullen (2010) proposed a 'hybrid' proto-South China Sea model that involved limited southward proto-South China Sea subduction and some extrusion. The hybrid model accommodated some geological observations including a more widespread Sarawak orogeny and Paleogene compression within the Dangerous Grounds and north-central Palawan (Cullen, 2010). However, the hybrid model did not fully resolve the 'space problems' created by north-south South China Sea opening and required the Sabah orogeny to be a secondary phase of NW Borneo orogenic uplift (Cullen, 2010). Our double-sided proto-South China Sea subduction model agrees with Cullen (2010) that far less southward proto-South China Sea subduction has occurred than indicated by many published models (e.g., Hall, 2012). By implementing northward subduction of the 'proto-South China Sea north slabs', our model is able to accommodate the space required for South China Sea opening while preserving the traditional view of that the 'Sabah orogeny' was produced by collision of the Dangerous Grounds with Borneo during the Mid-Miocene (Hutchison et al., 2000; Holloway, 1982).

\subsubsection{Summary: A slab-based proto-South China Sea Plate tectonic model}

In this study, we have outlined a new, testable protoSouth China Sea Plate tectonic model based on slab constraints. Our hypotheses are as follows.

(1) The proto-South China Sea existed between the South China-Eurasian continental margin and Borneo in the Early to Mid-Cenozoic. The proto-South China Sea eastern limit was $\sim 500 \mathrm{~km}$ east of the present Manila trench. The proto-South China Sea was consumed by double-sided subduction to the north and south between the Eocene and Mid-Miocene.

(2) The southern proto-South China Sea slabs subducted southwards under Borneo as Borneo rotated counterclockwise during the Eocene to Early Oligocene and possibly later. The 'Sarawak orogeny' at NW Borneo occurred near the end of the southward proto-South China Sea subduction.

(3) The northern proto-South China Sea slabs were subducted northwards (or 'in-place' within a mantle reference frame) under the Dangerous Grounds and north Palawan during South China Sea extension and seafloor spreading during the Earliest Oligocene $\sim 34$ Ma to Mid-Miocene 20 to 15 Ma. Northward proto-South China Sea subduction occurred in a 'self-subduction' fashion that is reminiscent of western Mediterranean tectonics since the Oligocene. The southern Dangerous Grounds leading edge was an active margin and collided with Borneo at 20 or 15 Ma. This collision initiated the Sabah orogeny at NW Borneo. An active volcanic arc existed along the southern Dangerous Grounds during South China Sea opening. We suggest this arc may have been underthrust beneath NW Borneo during collision of the Dangerous Grounds and Borneo at $\sim 20$ to $15 \mathrm{Ma}$.

\subsection{A Plate Tectonic Test for Tomographic Image Quality}

The tectonic interpretation of fast tomographic anomalies within the mantle is often non-unique, particularly if slab seismicity is absent. For example, it is often controversial whether fast tomographic anomalies are a slab, a tomographic artifact, or some other thermo-chemical feature. Helpful insights are often provided by tomographic resolution tests that involve inversion and attempted recovery of a known, synthetic seismic velocity model (e.g., synthetic slab test or checkerboard tests) (Figs. 1b to 1d) (cf., Rawlinson et al., 2014). These standard resolution tests have limitations, however, and the tomographic inversion itself has inherent parameter and resolution uncertainties that are not well-quantified and highly dependent on source and receiver locations (e.g., Fig. 1e) (Rawlinson et al., 2014). These uncertainties can often result in wide-ranging tectonic interpretations in regions such as the South China Sea. Our slab workflow is an independent plate tectonic test for tomographic imaging that can complement seismological methods.

\subsubsection{Challenges for plate tectonic tests}

Our 'plate tectonic test' for slab imaging is most applicable to areas that have well-constrained plate reconstruction boundary conditions, optimally, through a 'global plate tectonic circuit' (e.g., Seton et al., 2012). When global plate circuit constraints are less certain, as in East Asia, absolute plate positioning and regional seafloor spreading constraints (e.g., the South China Sea) are often sufficient if used together. In tectonically complex regions, slab interpretation uniqueness can be more fully tested because unfolded slabs must fit within multiple tectonic events in time and space, such as the initial subduction of the proto-South China Sea followed by a later subduction of the South China Sea along the Manila trench (Fig. 7). The plate tectonic test shown here will also yield better results when slab anomalies are sufficiently large relative to the tomographic resolution uncertainty, which is the case for the proto-South China Sea slabs in this study that exceed 1000 km N-S by $1500 \mathrm{~km} \mathrm{E-W} \mathrm{(Fig.} \mathrm{5b).}$

Our plate tectonic test is dependent on slab unfolding, 
which is the attempt to structurally restore a mapped slab back to the Earth surface to estimate its pre-subduction geometry (Fig. 2). Previous studies have applied slab unfolding to investigate subduction zones within the Mediterranean, the Tethyan realm, the SW Pacific and East Asia (Wu et al., 2016; Bezada et al., 2013; Lister et al., 2012; Hafkenscheid et al., 2006). Wu et al. (2016) further developed a method to integrate mapped and unfolded slab constraints within a quantitative plate reconstruction, which was applied to reconstruct East Asia since 52 Ma from 28 unfolded East Asia slabs (Wu et al., 2016).

A potential concern for slab mapping and unfolding is whether subducted slabs are distorted beyond recognition or even vanish within the mantle over time due to thermal erosion (i.e., loss of its thermal anomaly over time due to heating within the mantle). The study of $\mathrm{Wu}$ et al. (2016) indicated sufficient slab anomalies could be recovered within the upper $1300 \mathrm{~km}$ of the East Asian mantle to account for East Asia subduction since $52 \mathrm{Ma}$. Other published studies suggest slab anomalies can be sufficiently recovered even down to the coremantle boundary at $2980 \mathrm{~km}$ depths (van der Meer et al., 2017, 2009), which is also consistent with predictions from many geodynamic models (e.g., Tan et al., 2002).

\section{CONCLUSIONS}

Mapping and unfolding of slabs from SE Asia mantle tomographic images supports the following conclusions on South China Sea and proto-South China Sea Plate tectonics.

(a) Seismic tomography shows two swaths of subhorizontal, slab-like tomographic anomalies under the present South China Sea and North Borneo (Figs. 4, 5) that we infer to be subducted lithospheric remnants of the hypothesized protoSouth China Sea. The 'proto-South China Sea north slabs' were mapped at 450 to $700 \mathrm{~km}$ depths under the present South China Sea and westernmost Philippine Sea Plate. The 'protoSouth China Sea south slabs' underlie the southern South China Sea and northern Borneo at 750 to $900 \mathrm{~km}$ depths.

(b) Slab mapping and unfolding indicate the EurasiaSouth China Sea once extended 400 to $500 \mathrm{~km}$ east of the present Manila trench (Figs. 4a, 5a).

(c) Both the unfolded 'proto-South China Sea north slabs' and unfolded Eurasia-South China Sea show similar eastern edges that trend N-S and terminate $\sim 500 \mathrm{~km}$ east of the present Manila trench (Fig. 5a). When reconstructed within a plate model (Fig. 7, ESM2 ProtoSCS_plate_model_movie.mov), the restored eastern edges fit together as a shared South China Sea/proto-South China Sea N-S plate boundary transform.

(d) The proto-South China Sea existed in the Early to Mid-Cenozoic between North Borneo and South China. The proto-South China Sea was consumed by double-sided subduction between the Eocene and Mid-Miocene $\sim 15 \mathrm{Ma}$, as follows: (1) Counter-clockwise Borneo rotation initiated southward subduction of the proto-South China Sea under Borneo during the Mid- to Late Eocene, or later. The southward subducted proto-South China Sea lithosphere is represented today by the 'proto-South China Sea south slabs'. The Sarawak orogeny marked the end of the southward proto-South China Sea subduction. (2) South China Sea extension and seafloor spreading after $\sim 34 \mathrm{Ma}$ initiated northward subduction of the proto-South
China Sea under the Dangerous Grounds and North Palawan. The northward subducted proto-South China Sea is represented today by the 'proto-South China Sea north slabs' under the South China Sea between 450 to $700 \mathrm{~km}$ depths. Our model predicts the formation of a mantle wedge under the South China Sea during seafloor spreading that suggests South China Sea opening was accompanied by a more vigorous asthenospheric circulation than previously recognized.

Northward subduction of the proto-South China Sea terminated when the Dangerous Grounds leading edge collided with NW Borneo at 20 to $15 \mathrm{Ma}$ (i.e., Sabah orogeny). Our model predicts the existence of a southern South China Sea volcanic arc at the Dangerous Grounds leading edge. The remnant arc has not been identified but we suggest the arc was underthrusted under northern Borneo during collision.

(e) Slab unfolding offers an alternative 'plate tectonic test' for tomographic images of subduction zones that can complement seismic-based resolution tests. Our plate tectonic test of South China Sea tomography indicates the 'proto-South China Sea north slabs' anomalies are tectonically viable as the protoSouth China Sea and are not tomographic artifacts or older stagnant slabs.

\section{ACKNOWLEDGMENTS}

We thank JES special issue guest editor Prof. Hua-Wei Zhou for inviting this paper. We also thank Prof. Zhou for his role in organizing an informative 2016 workshop on geophysical imaging in Qingdao, China, where portions of this paper were presented. We are grateful to JES staffs for support and help with this JES special issue. Jean-Claude Sibuet is thanked for sharing South China Sea expertise and insightful feedback on the proto-South China Sea reconstructions. Yiduo Liu and Yi-Wei Chen provided helpful comments on the draft manuscript. Two anonymous reviewers contributed thoughtful and constructive comments that improved the final paper. Please see the supplementary data section for a proto-South China Sea plate reconstruction movie file and digital GPlates plate reconstruction files. The final publication is available at Springer via https://doi.org/10.1007/s12583-017-0813-X.

Electronic Supplementary Materials: Supplementary materials (ESM1 ProtoSCS_GPlates_files.rar; ESM2 ProtoSCS_plate_ model_movie.mov) are available in the online version of this article at https://doi.org/10.1007/s12583-017-0813-x.

Open Access This article is distributed under the terms of the Creative Commons Attribution 4.0 International License (http://creativecommons.org/licenses/by/4.0/), which permits unrestricted use, distribution, and reproduction in any medium, provided you give appropriate credit to the original author(s) and the source, provide a link to the Creative Commons license, and indicate if changes were made.

\section{REFERENCES CITED}

Bai, Y. L., Wu, S. G., Liu, Z., et al., 2015. Full-Fit Reconstruction of the South China Sea Conjugate Margins. Tectonophysics, 661: 121-135. https://doi.org/10.1016/j.tecto.2015.08.028

Barckhausen, U., Engels, M., Franke, D., et al., 2014. Evolution of the 
South China Sea: Revised Ages for Breakup and Seafloor Spreading. Marine and Petroleum Geology, 58: 599-611. https://doi.org/10.1016/j.marpetgeo.2014.02.022

Bezada, M. J., Humphreys, E. D., Toomey, D. R., et al., 2013. Evidence for Slab Rollback in Westernmost Mediterranean from Improved Upper Mantle Imaging. Earth and Planetary Science Letters, 368: 51-60. https://doi.org/10.1016/j.eps1.2013.02.024

Boyden, J. A., Müller, R. D., Gurnis, M., et al., 2011. Next-Generation Plate-Tectonic Reconstructions Using GPlates. In: Keller, G. R., Baru, C., eds. Geoinformatics: Cyber Infrastructure for the Solid Earth Sciences. Cambridge University Press, Cambridge. 95-113

Briais, A., Patriat, P., Tapponnier, P., 1993. Updated Interpretation of Magnetic Anomalies and Seafloor Spreading Stages in the South China Sea: Implications for the Tertiary Tectonics of Southeast Asia. Journal of Geophysical Research: Solid Earth, 98(B4): 6299-6328. https://doi.org/10.1029/92jb02280

Cullen, A. B., 2010. Transverse Segmentation of the Baram-Balabac Basin, NW Borneo: Refining the Model of Borneo's Tectonic Evolution. Petroleum Geoscience, 16(1): 3-29. https://doi.org/10.1144/1354079309-828

Cullen, A. B., Zechmeister, M. S., Elmore, R. D., et al., 2012. Paleomagnetism of the Crocker Formation, Northwest Borneo: Implications for Late Cenozoic Tectonics. Geosphere, 8(5): 1146-1169. https://doi.org/10.1130/ges00750.1

Domeier, M., Doubrovine, P. V., Torsvik, T. H., et al., 2016. Global Correlation of Lower Mantle Structure and Past Subduction. Geophysical Research Letters, 43(10): 4945-4953. https://doi.org/10.1002/2016g1068827

Dziewonski, A. M., Anderson, D. L., 1981. Preliminary Reference Earth Model. Physics of the Earth and Planetary Interiors, 25(4): 297-356. https://doi.org/10.1016/0031-9201(81)90046-7

Engdahl, E. R., van der Hilst, R., Buland, R., 1998. Global Teleseismic Earthquake Relocation with Improved Travel Times and Procedures for Depth Determination. Bulletin of the Seismological Society of America, 88(3): 722-743

Engdahl, E. R., Villaseñor, A., 2002. Global Seismicity: 1900-1999. In: Lee, W. H. K., Kanamori, H., Jennings, P. C., et al., eds., International Handbook of Earthquake and Engineering Seismology, Part A. Academic Press, Cambridge. 665-690

Faccenna, C., Becker, T. W., Auer, L., et al., 2014. Mantle Dynamics in the Mediterranean. Reviews of Geophysics, 52(3): 283-332. https://doi.org/10.1002/2013rg000444

Fan, J. K., Zhao, D. P., Dong, D. D., et al., 2017. P-Wave Tomography of Subduction Zones around the Central Philippines and Its Geodynamic Implications. Journal of Asian Earth Sciences, 146: 76-89. https://doi.org/10.1016/j.jseaes.2017.05.015

Franke, D., Barckhausen, U., Heyde, I., et al., 2008. Seismic Images of a Collision Zone Offshore NW Sabah/Borneo. Marine and Petroleum Geology, 25(7): 606-624. https://doi.org/10.1016/j.marpetgeo.2007.11.004

Fukao, Y., Obayashi, M., Inoue, H., et al., 1992. Subducting Slabs Stagnant in the Mantle Transition Zone. Journal of Geophysical Research: Solid Earth, 97(B4): 4809-4822. https://doi.org/10.1029/91jb02749

Fuller, M., Ali, J. R., Moss, S. J., et al., 1999. Paleomagnetism of Borneo. Journal of Asian Earth Sciences, 17(1/2): 3-24. https://doi.org/10.1016/s0743-9547(98)00057-9

Goes, S., Agrusta, R., van Hunen, J., et al., 2017. Subduction-Transition Zone Interaction: A Review. Geosphere, 13(3): 644-664. https://doi.org/10.1130/ges01476.1
Hafkenscheid, E., Wortel, M. J. R., Spakman, W., 2006. Subduction History of the Tethyan Region Derived from Seismic Tomography and Tectonic Reconstructions. Journal of Geophysical Research: Solid Earth, 111(B8): B08401. https://doi.org/10.1029/2005jb003791

Hall, R., 2002. Cenozoic Geological and Plate Tectonic Evolution of SE Asia and the SW Pacific: Computer-Based Reconstructions, Model and Animations. Journal of Asian Earth Sciences, 20(4): 353-431. https://doi.org/10.1016/s1367-9120(01)00069-4

Hall, R., 2012. Late Jurassic-Cenozoic Reconstructions of the Indonesian Region and the Indian Ocean. Tectonophysics, 570/571: 1-41. https://doi.org/10.1016/j.tecto.2012.04.021

Hall, R., Spakman, W., 2015. Mantle Structure and Tectonic History of SE Asia. Tectonophysics, 658: 14 45. https://doi.org/10.1016/j.tecto.2015.07.003

Hinz, K., Fritsch, J., Kempter, E. H. K., et al., 1989. Thrust Tectonics along the North-Western Continental Margin of Sabah/Borneo. Geologische Rundschau, 78(3): 705-730. https://doi.org/10.1007/bf01829317

Holloway, N. H., 1982. North Palawan Block, Philippines-Its Relation to Asian Mainland and Role in Evolution of South China Sea. AAPG Bulletin, 66(9): 1355. https://doi.org/10.1306/03b5a7a5-16d1-11d7$8645000102 \mathrm{c} 1865 \mathrm{~d}$

Huang, Z. C., Zhao, D. P., Wang, L., 2015. P Wave Tomography and Anisotropy beneath Southeast Asia: Insight into Mantle Dynamics. Journal of Geophysical Research: Solid Earth, 120(7): 5154-5174. https://doi.org/10.1002/2015jb012098

Hutchison, C. S., Bergman, S. C., Swauger, D. A., et al., 2000. A Miocene Collisional Belt in North Borneo: Uplift Mechanism and Isostatic Adjustment Quantified by Thermochronology. Journal of the Geological Society, 157(4): 783-793. https://doi.org/10.1144/jgs.157.4.783

Hutchison, C. S., 2010. Oroclines and Paleomagnetism in Borneo and South-East Asia. Tectonophysics, 496(1/2/3/4): 53-67. https://doi.org/10.1016/j.tecto.2010.10.008

Hutchison, C. S., 1996. The 'Rajang Accretionary Prism' and 'Lupar Line' Problem of Borneo. Geological Society, London, Special Publications, 106(1): 247-261. https://doi.org/10.1144/gsl.sp.1996.106.01.16

Koulakov, I., 2011. High-Frequency P and S Velocity Anomalies in the Upper Mantle beneath Asia from Inversion of Worldwide Traveltime Data. Journal of Geophysical Research: Solid Earth, 116(B4): B04301. https://doi.org/10.1029/2010jb007938

Legendre, C. P., Zhao, L., Chen, Q. F., 2015. Upper-Mantle Shear-Wave Structure under East and Southeast Asia from Automated Multimode Inversion of Waveforms. Geophysical Journal International, 203(1): 707-719. https://doi.org/10.1093/gji/ggv322

Li, C., van der Hilst, R. D., Engdahl, E. R., et al., 2008. A New Global Model for P Wave Speed Variations in Earth's Mantle. Geochemistry, Geophysics, Geosystems, $\quad 9(5)$ Q $\quad$ Q05018. https://doi.org/10.1029/2007gc001806

Li, C., van der Hilst, R. D., 2010. Structure of the Upper Mantle and Transition Zone beneath Southeast Asia from Traveltime Tomography. Journal of Geophysical Research: Solid Earth, 115(B7): B07308. https://doi.org/10.1029/2009jb006882

Li, C.-F., Xu, X., Lin, J., et al., 2014. Ages and Magnetic Structures of the South China Sea Constrained by Deep Tow Magnetic Surveys and IODP Expedition 349. Geochemistry, Geophysics, Geosystems, 15(12): 4958-4983. https://doi.org/10.1002/2014gc005567

Lister, G. S., White, L. T., Hart, S., et al., 2012. Ripping and Tearing the Rolling-Back New Hebrides Slab. Australian Journal of Earth Sciences, 59(6): 899-911. https://doi.org/10.1080/08120099.2012.686454

Lu, R.-Q., Suppe, J., He, D.-F., et al., 2013. Deep Subducting Slab 
Reconstruction and Its Geometry, Kinematics: A Case Study for the Tonga-Kermadec Slab from Tomography. Chinese Journal Geophysics, 56(11): 3837-3845

Obayashi, M., Yoshimitsu, J., Nolet, G., et al., 2013. Finite Frequency Whole Mantle P Wave Tomography: Improvement of Subducted Slab Images. Geophysical Research Letters, 40(21): 5652-5657. https://doi.org/10.1002/2013g1057401

Pubellier, M., Morley, C. K., 2014. The Basins of Sundaland (SE Asia): Evolution and Boundary Conditions. Marine and Petroleum Geology, 58: 555-578. https://doi.org/10.1016/j.marpetgeo.2013.11.019

Rangin, C., Spakman, W., Pubellier, M., et al., 1999. Tomographic and Geological Constraints on Subduction along the Eastern Sundaland Continental Margin (South-East Asia). Bulletin de la Societe Geologique de France, 170(6): 775-788

Rawlinson, N., Fichtner, A., Sambridge, M., et al., 2014. Chapter OneSeismic Tomography and the Assessment of Uncertainty. In: Renata, D., ed., Advances in Geophysics. Elsevier, 55: 1-76. http://www.sciencedirect.com/science/article/pii/S0065268714000028

Replumaz, A., Tapponnier, P., 2003. Reconstruction of the Deformed Collision Zone between India and Asia by Backward Motion of Lithospheric Blocks. Journal of Geophysical Research: Solid Earth, 108(B6): 2285. https://doi.org/10.1029/2001jb000661

Schlüter, H. U., Hinz, K., Block, M., 1996. Tectono-Stratigraphic Terranes and Detachment Faulting of the South China Sea and Sulu Sea. Marine Geology, 130(1/2): 39-78. https://doi.org/10.1016/0025-3227(95)00137-9

Seton, M., Müller, R. D., Zahirovic, S., et al., 2012. Global Continental and Ocean Basin Reconstructions since 200 Ma. Earth-Science Reviews, 113(3/4): 212-270. https://doi.org/10.1016/j.earscirev.2012.03.002

Sibuet, J.-C., Yeh, Y.-C., Lee, C.-S., 2016. Geodynamics of the South China Sea. Tectonophysics, 692: 98-119. https://doi.org/10.1016/j.tecto.2016.02.022

Sigloch, K., Mihalynuk, M. G., 2013. Intra-Oceanic Subduction Shaped the Assembly of Cordilleran North America. Nature, 496(7443): 50-56. https://doi.org/10.1038/nature12019

Spakman, W., Wortel, M. J. R., 2004. Tomographic View on Western Mediterranean Geodynamics. In: Cavazza, W., Roure, F. M., Spakman, W., et al., eds., The TRANSMED Atlas, The Mediterranean Region from Crust to Mantle. Springer-Verlag, Heidelberg. 31-52

Sun, W., Lin, C.-T., Zhang, C.-C., et al., 2016. Initiation and Evolution of the South China Sea: An Overview. Acta Geochimica, 35(3): 215-225

Tan, E., Gurnis, M., Han, L. J., 2002. Slabs in the Lower Mantle and Their Modulation of Plume Formation. Geochemistry, Geophysics, Geosystems, 3(11): 1-24. https://doi.org/10.1029/2001gc000238
Taylor, B., Hayes, D. E., 1983. Origin and History of the South China Sea Basin. In: Hayes, D. E., ed., The Tectonic and Geologic Evolution of Southeast Asian Seas and Islands: Part 2. American Geophysical Union, Washington D.C. Geophysical Monographs Series, 27: 23-56

Torsvik, T. H., Müller, R. D., Van der Voo, R., et al., 2008. Global Plate Motion Frames: Toward a Unified Model. Reviews of Geophysics, 46(3): 44. https://doi.org/10.1029/2007rg000227

van der Meer, D. G., Spakman, W., van Hinsbergen, D. J. J., et al., 2009. Towards Absolute Plate Motions Constrained by Lower-Mantle Slab Remnants. Nature Geoscience, 3(1): 36-40. https://doi.org/10.1038/ngeo708

van der Meer, D. G., van Hinsbergen, D. J. J., Spakman, W., 2017. Atlas of the Underworld: Slab Remnants in the Mantle, Their Sinking History, and a New Outlook on Lower Mantle Viscosity. Tectonophysics. https://doi.org/10.1016/j.tecto.2017.10.004

von Hagke, C., Philippon, M., Avouac, J.-P., et al., 2016. Origin and Time Evolution of Subduction Polarity Reversal from Plate Kinematics of Southeast Asia. Geology, 44(8): 659-662. https://doi.org/10.1130/g37821.1

Wu, J., Suppe, J., Lu, R. Q., et al., 2016. Philippine Sea and East Asian Plate Tectonics since $52 \mathrm{Ma}$ Constrained by New Subducted Slab Reconstruction Methods. Journal of Geophysical Research: Solid Earth, 121(6): 4670-4741. https://doi.org/10.1002/2016jb012923

Yan, P., Liu, H. L., 2004. Tectonic-Stratigraphic Division and Blind Fold Structures in Nansha Waters, South China Sea. Journal of Asian Earth Sciences, 24(3): 337-348. https://doi.org/10.1016/j.jseaes.2003.12.005

Zahirovic, S., Seton, M., Müller, R. D., 2014. The Cretaceous and Cenozoic Tectonic Evolution of Southeast Asia. Solid Earth, 5(1): 227-273. https://doi.org/10.5194/se-5-227-2014

Zahirovic, S., Müller, R. D., Seton, M., et al., 2015. Tectonic Speed Limits from Plate Kinematic Reconstructions. Earth and Planetary Science Letters, 418: 40-52. https://doi.org/10.1016/j.epsl.2015.02.037

Zahirovic, S., Matthews, K. J., Flament, N., et al., 2016. Tectonic Evolution and Deep Mantle Structure of the Eastern Tethys since the Latest Jurassic. Earth-Science Reviews, 162: 293-337. https://doi.org/10.1016/j.earscirev.2016.09.005

Zhao, D. P., 2015. The 2011 Tohoku Earthquake $\left(M_{\mathrm{w}}\right.$ 9.0) Sequence and Subduction Dynamics in Western Pacific and East Asia. Journal of Asian Earth Sciences, 98: 26-49. https://doi.org/10.1016/j.jseaes.2014.10.022

Zhou, D., Ru, K., Chen, H.-Z., 1995. Kinematics of Cenozoic Extension on the South China Sea Continental Margin and Its Implications for the Tectonic Evolution of the Region. Tectonophysics, 251(1/2/3/4): 161177. https://doi.org/10.1016/0040-1951(95)00018-6 